\title{
That is why people are frightened of needles!
}

\author{
A. Amirjamshidi • K. Abbassioun • G. Amirjamshidi
}

Published online: 11 February 2009

(C) Springer-Verlag 2009

\begin{abstract}
"Dear God, forgive me, please, please forgive me (crying and crying). I have done something wrong, ....very wrong! What will happen to me if you don't forgive me? Please, please the almighty and merciful God. I had been in love with my husband who strongly wished to have a baby but I couldn't get pregnant. I did pray a lot and searched for all kinds of medical and spiritual treatments but all in vain. At last, I found an ugly girl grown in a poor family and arranged for my husband to marry her to deliver a baby for us and then divorce her. She delivered a son and became the lovely queen in my house. It was intolerable for me. Oh my God, I went out of my mind and put a needle in his head, so he died the day after. She got pregnant again and I could not refuse killing the second baby-son in a month time. She delivered the 3rd. baby and this time I poisoned the mother and kept the son for myself and my husband. Now, he is a young man and my husband has passed away. Heavens, when I look in his eyes, I remember the three drops of blood shed by my hands. I am sure; I will be to the bottom of hell if you don't forgive me, my mighty God."
\end{abstract}

"Three blood droplets" by Sadegh Hedayat (http://sokhan.com)

"Child abuse" is one of the overwhelming harmful problems the physicians are engaged with. The history of such maltreatment behaviors goes back for many centuries. One of the uncommon inventions for child abuse has been using "sewing needles". This has been reported from

A. Amirjamshidi $\cdot$ K. Abbassioun · G. Amirjamshidi Azad University,

Tehran, Iran

\section{A. Amirjamshidi $(\bowtie)$}

Sina Hospital, Tehran University of Medical Science (TUMS),

Tehran, Iran

e-mail: abamirjamshidi@yahoo.com different countries such as Germany, United States, Turkey, Poland, Hungary, Yugoslavia, and Iran [1, 2, 4, 6-8]. This kind of child abuse is well known in some communities and has even been mentioned in one of the Iranian famous historian novels "Three blood droplets" by Sadegh Hedayat [5].

Insertion of sewing needles is performed through the patent fontanels for the purpose of child abuse, and the offending person is probably and usually the stepmother but a psychopathic mother, aunt, stepsister, and babysitter have been mentioned as the other offenders in the literature [1,7]. If the first homicide attempt was not successful, a second, third, or even more needling attempts might have been performed to kill the victim [2]. There are also reports of insertion of needles to the other parts of victims' body such as chest and abdomen $[1,2,8]$.

In the western communities, it is not strange for married men to have fiancés and even deliver babies in this new relationship. In the eastern or more religious societies, "polygamy" is more common among some families suffering from "sterility" of the lady. This may lead to polygamy, wherein adapting a child growing in orphanages is not plausible (Fig. 1).

If the patient is referred in the acute phase with fever and signs and symptoms of raised ICP, it is better to take it out following a CT scan and in proper operative situation. Taking whole body radiographs is mandatory in such cases where a case of child abuse is suspected. What do we do if the patient is referred in a so-called chronic stage? In accordance with the results of the long-term follow-up of the cases harboring intracranial foreign materials and missile fragments, there is no absolute indication for removing the retained foreign particle $[3,8]$. There are some relative indications mostly 


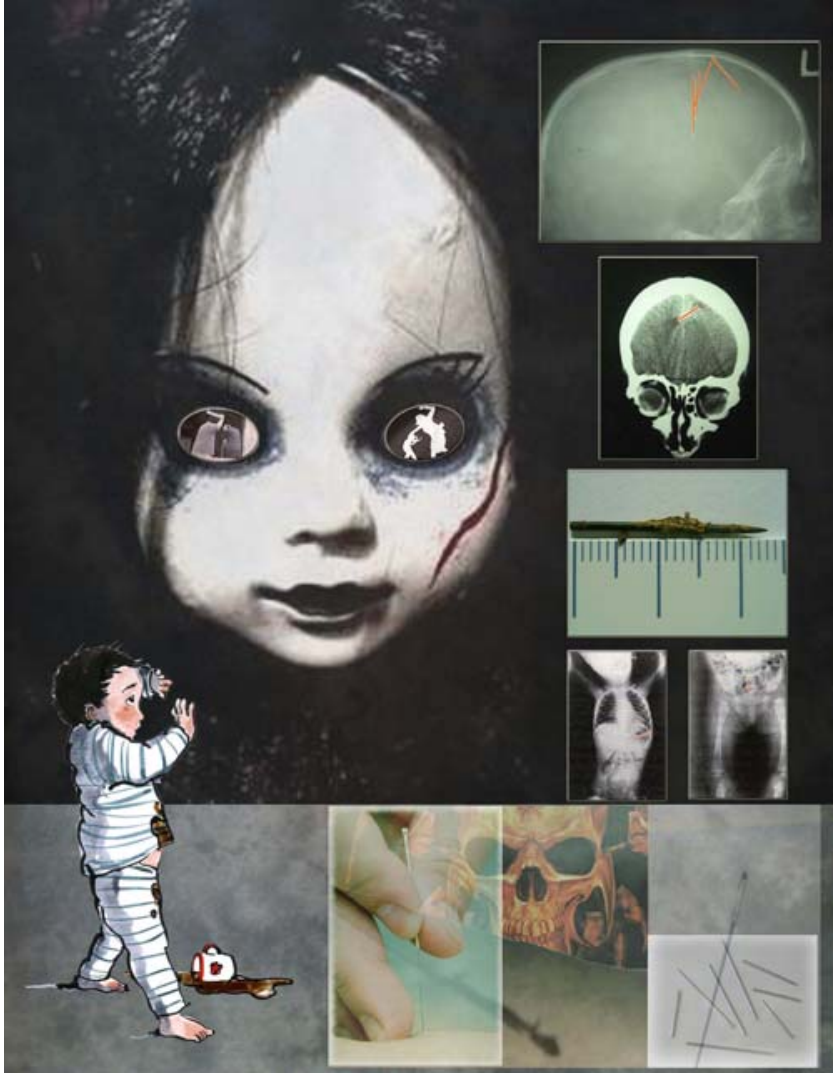

Fig. 1 The figure shows the cover illustration

in accordance with the patient's will and after full disclosure of the possible complications of the surgical interventions and for the possible better control of epilepsy $[2,6]$.

How do we approach these patients? Should we or should we not inform the patient and the family about the assault? In "acute stage", surgery may be inevitable, and everything will be declared to the family at least to save the victim from further abuse. But in cases referred later as the so-called incidental finding or unrelated causation, i.e., the patients diagnosed in the chronic stage, there may be a great dilemma. The family will become aware of what had happened a long time ago even though it has fallen in a rather uncomplicated course [6,7]. The management is certainly ambiguous and will depend upon the rules and attorney consultations to prevent unpredictable reactions, and it is suggested to handle the matter more cautiously.

\section{References}

1. Abbassioun K, Ameli NO, Morshed AA (1979) Intracranial sewing needles, review of 13 cases. J Neurl Neurosurg Phsychiatry 42:1046-1049

2. Ameli NO, Alimohammadi A (1970) Attempted infanticide by insertion of sewing needles through fontanelles. Report of 2 cases. J Neurosurg 33:721-723

3. Amirjamshidi A, Abbassioun K, Rahmat H (2003) Minimal debridement or simple wound closure as the only surgical treatment in war victims with low velocity penetrating head injuries. Indications and management protocol based upon more than 8 years follow up of 99 cases from Iran-Iraque conflict. Surg Neurol 60:105-111

4. Balak N, Güçlü G, Karaca I, Aksoy S (2008) Intracranially retained sewing needle in a child: does the rust on the needle have any implication? Eur J Trauma Emerg Surg 34:159-62

5. Hedayat S (1951) Se Ghatreh khoon (three drops of blood). Amirkabir, Tehran In Persian

6. Tuncer N, Yayci N, Ekinci G, Inanici MA, Elmaci I (2007) Intracranial sewing needles in a man with seizure: a case of child abuse. Forensic Sci Int 168:212-214

7. Unal N, Babayigit A, Karababa S, Yilmaz S (2005) Asymptomatic intracranial sewing needle: an unsuccessful infanticide attempt? Pediatrics International 47:206-208

8. Yolas C, Aydin MD, Ozdikici M, Aydin N, Onder A (2007) Intracerebral sewing needle. Pediatr Neurosurg 43:421-423 